\author{
M. J. Holness • G. K. Greenwood • N. D. Smith • \\ M. C. Sugden
}

\title{
Hyperthyroidism impairs pancreatic beta cell adaptations to late pregnancy and maternal liporegulation in the rat
}

Received: 4 April 2005 / Accepted: 29 June 2005 / Published online: 5 October 2005

(C) Springer-Verlag 2005

\begin{abstract}
Aims/hypothesis: Hyperthyroidism modifies lipid dynamics (increased oxidation), impairs insulin action and can suppress insulin secretion. We therefore examined the impact of hyperthyroidism on the relationship between glucose-stimulated insulin secretion (GSIS) and insulin action, using late pregnancy as a model of physiological insulin resistance that is associated with compensatory insulin hypersecretion to maintain glucose tolerance. Our aim was to examine whether hyperthyroidism compromises the regulation of insulin secretion and the ability of insulin to modulate circulating lipid concentrations in late pregnancy. Materials and methods: Hyperthyroidism was induced by tri-iodothyronine $\left(\mathrm{T}_{3}\right)$ administration from day 17 to 19 of pregnancy. GSIS was assessed during an IVGTT and during hyperglycaemic clamps in vivo and in vitro, using step-up and -down islet perifusions. Results: Hyperthyroidism in pregnancy elevated the glucose threshold for GSIS and impaired GSIS at low and high glucose concentrations in islet perifusions. In the intact animal, insulin secretion (after bolus glucose) was more rapidly curtailed following removal of the glucose stimulus to secretion. In contrast, GSIS was maintained during protracted hyperglycaemia (hyperglycaemic clamps) in the hyperthyroid pregnant state in vivo. Conclusions/interpretation: Hyperthyroidism in vivo during late pregnancy blunts GSIS in subsequently isolated and
\end{abstract}

M. J. Holness · G. K. Greenwood · N. D. Smith · M. C. Sugden Centre for Diabetes and Metabolic Medicine,

Institute of Cell and Molecular Science,

St Bartholomew's and the Royal London

School of Medicine and Dentistry,

Queen Mary, University of London,

London, UK

M. C. Sugden $(\bowtie)$

Centre for Diabetes and Metabolic Medicine,

Institute of Cell and Molecular Science,

4 Newark Street, Whitechapel,

London, E1 2AT, UK

e-mail: m.c.sugden@qmul.ac.uk

Tel.: +44-20-78822355

Fax: +44-20-78822186 perifused islets at low and high glucose concentrations. It also adversely affects GSIS under conditions of an acute glucose challenge in vivo. In contrast, GSIS is maintained during sustained hyperglycaemia in vivo, suggesting that in vivo factors can rescue GSIS. The ability of insulin to suppress systemic lipid levels during hyperglycaemic clamps was impaired. We therefore suggest that higher circulating lipids may preserve GSIS under conditions of sustained hyperglycaemia in the hyperthyroid pregnancy.

Keywords Insulin resistance $\cdot$ Insulin secretion Islet perifusions $\cdot$ Pregnancy $\cdot T_{3}$

Abbreviations $\Delta G_{0-30}$ : incremental blood glucose values integrated over the 30 -min period after the bolus injection of glucose - GIR: glucose infusion rate - GSIS: glucose-stimulated insulin secretion $\cdot \Delta I_{0-30}$ : incremental plasma insulin values integrated over the 30 -min period after bolus injection of glucose $\cdot \Delta I_{0-60}$ : incremental plasma insulin values integrated over the period of chronic glucose infusion $\cdot \Delta I_{60-140}$ : incremental plasma insulin values integrated over the 80-min period of islet perifusion $\cdot k$ : rate of glucose disappearance . $\mathrm{T}_{3}$ : tri-iodothyronine $\cdot$ TAG: triacylglycerol

\section{Introduction}

In healthy individuals, there is a feedback loop between insulin sensitivity and insulin secretion $[1,2]$. This may involve common factors contributing to both insulin resistance and pancreatic beta cell function, or factors influencing insulin sensitivity, pancreatic beta cell function and the feedback mechanisms that link them [3]. Inadequate compensatory hypersecretion of insulin to counter insulin resistance is critical to the pathology of type 2 diabetes [3]. Pregnancy is a progressive state of maternal insulin resistance [4-6] (reviewed in [7]), which in healthy pregnancies is accompanied by reciprocal increases in insulin secretion (see $[5,8])$. Gestational diabetes occurs in women who secrete insufficient insulin to compensate for lowered in- 
sulin sensitivity during the third trimester [9] (reviewed in [3]).

In addition to glucoregulation, insulin suppresses adipocyte lipolysis (see [10]) and hepatic VLDL-triacylglycerol (TAG) secretion [11-13]. Elevated plasma NEFA concentrations predict the transition from IGT to type 2 diabetes [14, 15], suggesting that impaired pancreatic beta cell function is related to inadequate suppression of lipolysis. Despite maternal hyperinsulinaemia, pregnancy is also associated with hypertriacylglycerolaemia [16-19]. Insulin hypersecretion is reduced in concert with normalisation of maternal TAG levels by the administration of the fibrate WY14,643 in pregnancy [5]. Hyperthyroidism, which elicits adipocyte insulin resistance with regard to anti-lipolysis [20], can cause glucose intolerance in susceptible individuals [21] and has deleterious effects on pregnancy outcome [22]. The exact relationships between adipocyte insulin resistance, elevated NEFA and/or TAG, and pancreatic beta cell dysfunction during pregnancy are not yet established. We therefore investigated the impact of hyperthyroidism on the feedback between insulin sensitivity and pancreatic beta cell function in late pregnancy in relation to the suppression by insulin of systemic lipid levels. It is well known that hyperthyroidism modifies lipid dynamics (increased lipolysis and oxidation), impairs insulin action, and can also suppress insulin secretion [20, 23-28]. Our aim was to examine whether hyperthyroidism compromises the regulation of insulin secretion and the ability of insulin to modulate fuel homeostasis in late pregnancy, which itself is characterised by a form of insulin resistance that is associated with altered lipid dynamics, but can be countered by enhanced insulin secretion. We have previously argued that insulin hypersecretion during pregnancy may be geared to regulation of maternal lipid handling, and our present study shows that this action is impaired by hyperthyroidism. Our new data also show that glucose intolerance can be induced by hyperthyroidism in pregnancy due to a diabetogenic effect of hyperthyroidism on the islet itself. We further demonstrate that this adverse effect of hyperthyroidism in late pregnancy can be reversed in vivo, if there is sustained delivery of glucose, which has been shown by others to repartition fatty acid metabolism from oxidation to esterification.

\section{Materials and methods}

Materials Reagents were purchased from Roche Diagnostics (Lewes, Sussex, UK) or Sigma (Poole, Dorset, UK). Kits for determination of insulin (by ELISA, using rat insulin as standard) and glucose (by a glucose oxidase method) were purchased from Mercodia (Uppsala, Sweden) and Roche Diagnostics. Wako kits for the spectrophotometric determination of NEFA and TAG levels were purchased from Alpha Labs (Eastleigh, Hants., UK).

Animal treatment Studies were conducted in adherence to the UK Animal Scientific Procedures Act (1986). Female Wistar rats (Charles River, Margate, Kent, UK) were maintained at $21 \pm 2^{\circ} \mathrm{C}$ (12-h light-dark cycle), with free access to standard diet (Special Diet Services, Witham, Essex, UK; $52 \%$ carbohydrate, $15 \%$ protein, 3\% lipid, $30 \%$ non-digestible residue [by weight]; $10.92 \mathrm{~kJ}$ metabolisable energy/g) and water. Rats were time-mated by the appearance of sperm plugs (day 0 of pregnancy). Pregnant rats with less than eight fetuses were excluded.

Pregnant rats were rendered hyperthyroid by subcutaneous injection of tri-iodothyronine $\left(\mathrm{T}_{3} ; 1 \mathrm{mg} / \mathrm{kg}\right.$ body weight per day; 3 days from day 17 to 19 of pregnancy); euthyroid control rats were injected with hormone solvent (10 mmol/1 NaOH, 0.03\% BSA) [20, 29]. This dose and period of $\mathrm{T}_{3}$ treatment were selected on the basis of previous studies that demonstrated $T_{3}$-induced changes in metabolic function and gene expression, together with cardiac hypertrophy (results not shown). Although not measured in this series of experiments, the dosage and period of treatment typically generate serum $\mathrm{T}_{3}$ concentrations of 15-20 nmol/1 [29] compared with normal $\mathrm{T}_{3}$ concentrations of about $1.5 \mathrm{nmol} / 1$ [20,30,31]. We elected to administer this treatment specifically during late pregnancy to avoid the potential effect of hyperthyroidism in modulating the expansion of beta cell mass that typically occurs during mid-pregnancy in response to the development of maternal insulin resistance, and because adiposetissue lipid metabolism is geared towards lipolysis rather than lipogenesis during late pregnancy. For in vivo studies, animals were fitted with chronic indwelling jugular cannulae (for infusion and sampling) with 6-8 days' recovery. Cannulae were filled with saline $(154 \mathrm{mmol} \mathrm{NaCl} / \mathrm{l})$ and plugged until the day of the experimental studies. Hyperglycaemic clamps and IVGTT were completed in conscious, unrestrained rats in the postabsorptive (6-h starved) state.

IVGTT An intravenous glucose bolus $(0.5 \mathrm{~g}$ glucose $/ \mathrm{kg}$ body weight) $[10,32]$ was administered via a chronic indwelling cannula. Blood samples $(100 \mu \mathrm{l})$ were withdrawn before glucose injection and at 2, 5, 10, 15 and $30 \mathrm{~min}$ after glucose injection. Aliquots $(50 \mu \mathrm{l})$ were deproteinised and the supernatant fractions assayed for glucose. The remainder was centrifuged $\left(10,000 \times g, 4^{\circ} \mathrm{C}\right)$, and plasma assayed for insulin. Insulin and glucose responses during the glucose tolerance test were used for calculation of the incremental insulin or glucose values integrated over the 30-min period after glucose injection $\left(\Delta I_{0-30}\right.$ and $\Delta G_{0-30}$, respectively). The rate of glucose disappearance $(k)$ was calculated from the slope of the regression line obtained with log-transformed glucose values from 5 to 15 min after glucose administration.

Islet perifusion Rats were injected with sodium pentobarbital $(60 \mathrm{mg} / \mathrm{ml} \mathrm{NaCl}[154 \mathrm{mmol} / \mathrm{l}] ; 1 \mathrm{ml} / \mathrm{kg}$ body weight i.p.). Once locomotor activity had ceased, pancreases were excised for islet preparation (collagenase digestion) and the rats killed. Isolated islets were collected into HEPESbuffered Hanks' balanced salts solution containing 5\% BSA. Insulin release was measured in a perifusion system, as described previously $[5,33]$. In this system, 50 islets 
were housed in small chambers on Millicell culture plate inserts (Sigma, Poole, Dorset, UK). Islets were perifused in basal medium (KRB containing HEPES [20 mmol/l] pH 7.4 , BSA [ $5 \mathrm{mg} / \mathrm{ml}]$ and glucose $[2 \mathrm{mmol} / \mathrm{l}]$ ) for $60 \mathrm{~min}$ at a flow rate of $1 \mathrm{ml} / \mathrm{min}$ at $37^{\circ} \mathrm{C}$ prior to collection of fractions. Glucose concentrations were then modified as indicated. Fractions $(2 \mathrm{ml})$ were collected at 2-min intervals and assayed for insulin and glucose. Insulin responses during the perifusion were used for calculation of the incremental insulin values integrated over the $80 \mathrm{~min}$ period of the perifusion $\left(\Delta I_{60-140}\right)$. In addition, to quantify insulin secretory responses, areas under the insulin curves were calculated for discrete 16-min periods: $\Delta 1$, during which the perifusate glucose concentration was increased from 2 to $8 \mathrm{mmol} / \mathrm{l} ; \Delta 2$, during which the perifusate glucose concentration was increased from 8 to $16 \mathrm{mmol} / 1 ; \Delta 3$, where the perifusate glucose concentrations were lowered from 16 to $2 \mathrm{mmol} / \mathrm{l}$; and $\Delta 4$, when perifusate glucose had been restored to basal.

Hyperglycaemic clamps After 30 min equilibration, a 25\% glucose solution was infused to maintain glycaemia at about $11 \mathrm{mmol} / 1$ in order to cause glucose-stimulated insulin secretion (GSIS) and thereby evaluate beta cell function in vivo. Blood and plasma samples, obtained at 5-min intervals thereafter for $60 \mathrm{~min}$, were assayed for glucose, insulin, NEFA and TAG. Blood glucose and plasma insulin, NEFA and TAG values obtained between 30 and $60 \mathrm{~min}$ 3after initiation of glucose infusion were used for calculation of mean steady-state concentrations. Insulin responses were used to calculate the incremental values integrated over the period of glucose infusion $\left(\Delta I_{0-60}\right)$. The steadystate rate of glucose infusion (GIR) was calculated as the mean GIR during the last 30 min of glucose infusion.

Table 1 Body weights, food intakes, and postabsorptive blood glucose and plasma insulin concentrations of pregnant euthyroid or hyperthyroid dams, and the number and weights of their fetuses

\begin{tabular}{|c|c|c|}
\hline & Euthyroid & Hyperthyroid \\
\hline $\begin{array}{l}\text { Body weight at day } 17 \\
\text { of pregnancy }(\mathrm{g})\end{array}$ & $327 \pm 5(12)$ & $315 \pm 6(11)$ \\
\hline $\begin{array}{l}\text { Body weight at day } 19 \\
\text { of pregnancy }(\mathrm{g})\end{array}$ & $363 \pm 8(12)$ & $328 * * \pm 6(11)$ \\
\hline $\begin{array}{l}\text { Mean food intake from days } \\
17 \text { to } 19 \text { of pregnancy }(\mathrm{g})\end{array}$ & $71.6 \pm 3.2(12)$ & $62.4 \pm 3.7(11)$ \\
\hline Mean fetal number per dam & $14 \pm 1(7)$ & $13 \pm 1(6)$ \\
\hline Mean fetal weight $(\mathrm{g})$ & $2.3 \pm 0.1(7)$ & $2.8 * \pm 0.1(6)$ \\
\hline Basal blood glucose $(\mathrm{mmol} / \mathrm{l})$ & $3.0 \pm 0.2(6)$ & $3.7 * * \pm 0.2(8)$ \\
\hline Basal plasma insulin $(\mu \mathrm{U} / \mathrm{ml})$ & $31 \pm 5(6)$ & $38 \pm 5(8)$ \\
\hline
\end{tabular}

Blood glucose and plasma insulin concentrations were determined using commercial kits. Data are means \pm SEM, with the numbers of rats or litters in parentheses. Mean fetal weight per litter was calculated from the individual weights of all fetuses in each litter. Mean fetal weight was calculated as the average of mean fetal weights of each litter, with numbers of litters given in parentheses ${ }^{*} p<0.05$ and $* * p<0.01$ for differences between euthyroid and hyperthyroid pregnant rats
Statistical analysis Results are mean \pm SEM, with the numbers of litters, rats or islet preparations in parentheses. Statistical analysis was performed by ANOVA followed by Fisher's post hoc tests for individual comparisons or Student's $t$-test as appropriate (Statview, Abacus Concepts, Berkeley, CA, USA). A $p$ value $<0.05$ was considered to be statistically significant.

\section{Results}

Hyperthyroidism during late pregnancy impairs maternal weight gain, but augments fetal weight Body weights and food intakes over the 3-day period of $\mathrm{T}_{3}$ treatment are shown in Table 1. Body weight progressively increased from day 0 to 19 of pregnancy (results not shown; see [34]). Body weights of euthyroid dams increased from day
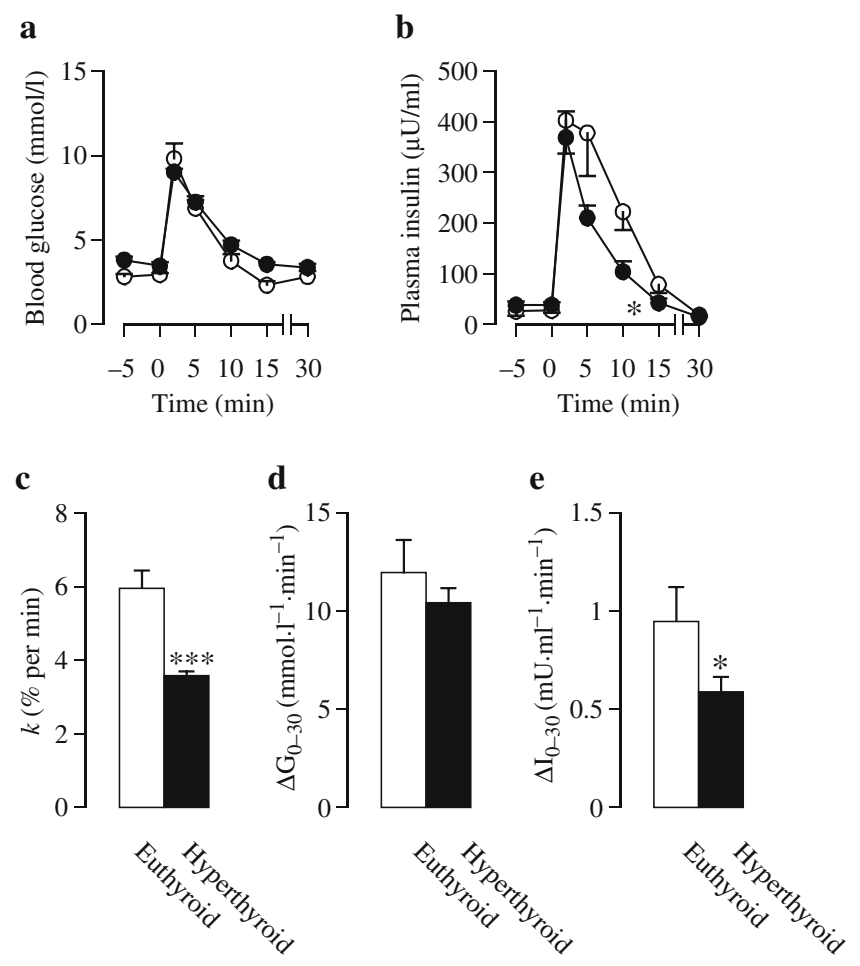

Fig. 1 Effects of hyperthyroidism during late pregnancy on glucose tolerance and insulin secretion in response to an acute glucose challenge in vivo. Blood samples were drawn from euthyroid or hyperthyroid 19-day pregnant rats before and at intervals after a single intravenous glucose bolus, for measurement of blood glucose and plasma insulin concentrations. Blood glucose (a) and plasma insulin (b) concentrations at times relative to administration of glucose bolus in euthyroid (open symbols) or hyperthyroid (closed symbols) 19-day pregnant rats. c Rates of glucose disappearance $(k$ values), calculated from the slopes of the regression lines obtained with log-transformed glucose values from 5 to $15 \mathrm{~min}$ after glucose administration. d, e Glucose and insulin responses during the acute glucose challenge were used to calculate the incremental blood glucose and plasma insulin values integrated over the 30 -min period after the injection of glucose $\left(\Delta G_{0-30}\right.$ and $\Delta I_{0-30}$, respectively). Results are means \pm SEM for six euthyroid and eight hyperthyroid pregnant rats. $* p<0.05$ and $* * * p<0.001$ for differences between euthyroid and hyperthyroid pregnant rats 
Table 2 Mean perifusate glucose concentrations and integrated AUC for insulin for discrete 16-min periods during islet perifusions

\begin{tabular}{|c|c|c|c|c|c|}
\hline & \multicolumn{2}{|c|}{ Mean glucose $(\mathrm{mmol} / \mathrm{l})$} & \multicolumn{2}{|l|}{$\Delta I\left(\mu \mathrm{U} \mathrm{ml} l^{-1} \min ^{-1}\right)$} & \multirow{2}{*}{$\begin{array}{l}\text { Decline in } \Delta \mathrm{I} \text { elicited by } \\
\text { hyperthyroidism }(\%)\end{array}$} \\
\hline & Euthyroid & Hyperthyroid & Euthyroid & Hyperthyroid & \\
\hline$\Delta 1$ & $6.4 \pm 0.2(9)$ & $5.9 \pm 0.1(4)$ & $132.3 \pm 33.3(9)$ & $20.5^{*} \pm 9.0$ & 85 \\
\hline$\Delta 2$ & $13.8 \pm 0.4(9)$ & $14.0 \pm 0.1$ & $868.7 \pm 122.9(9)$ & $162.7 * * * \pm 63.7$ & 81 \\
\hline$\Delta 3$ & $4.5 \pm 0.2(9)$ & $4.5 \pm 0.3$ & $1190.0 \pm 220.6(9)$ & $521.9^{*} \pm 249.5$ & 56 \\
\hline$\Delta 4$ & $2.4 \pm 0.2(9)$ & $2.3 \pm 0.1$ & $554.0 \pm 137.5(9)$ & $221.4 * \pm 105.2$ & 60 \\
\hline
\end{tabular}

Mean perifusate glucose concentrations and AUC for insulin were calculated as described (see Islet perifusion). The percentage decline in the insulin AUC for the discrete 16-min periods elicited by hyperthyroidism are also shown. Data are means \pm SEM, with the numbers of pregnant rats in parentheses

$* p<0.05$ and $* * * p<0.001$ for differences between euthyroid and hyperthyroid pregnant rats

17 to 19 of pregnancy by $11 \%$ (Table 1 ). Although no statistically significant effect of $\mathrm{T}_{3}$ administration on food intake was observed, body weight gain was markedly impaired (by $64 \% ; p<0.01$ ) (Table 1 ). Fetal numbers were not significantly affected by hyperthyroidism (Table 1). In contrast, mean fetal weight (calculated as the average of mean fetal weights for each litter) was increased by $22 \%$ by hyperthyroidism (Table 1) and, as a consequence, mean total litter weight was increased by $13 \%(p<0.05)$.

Hyperthyroidism during late pregnancy causes postabsorptive hyperglycaemia and decreased rates of glucose disappearance after an acute glucose challenge in vivo Basal (postabsorptive) glucose concentrations were increased (by 23\%; $p<0.01$ ) in hyperthyroid compared with euthyroid pregnant dams (Table 1). To assess glucose handling in vivo, glucose was administered as a single i.v. bolus. Blood glucose profiles during IVGTT are shown in Fig. 1a. Glucose disappearance rates ( $k$ values) were significantly decreased (by $40 \% ; p<0.001$ ) by hyperthyroidism (Fig. 1c). However, incremental glucose values integrated over the 30-min period after glucose injection $\left(\Delta G_{0-30}\right)$ were not statistically affected by hyperthyroidism (Fig. 1d).

GSIS in vivo in response to acute glucose challenge is impaired by hyperthyroidism during late pregnancy Insulin concentrations in the postabsorptive state were unaffected by hyperthyroidism (Table 1). Plasma insulin profiles during IVGTT are shown in Fig. 1b. Incremental insulin values integrated over the 30-min period after glucose injection $\left(\Delta I_{0-30}\right)$ (Fig. 1e) were significantly lowered by hyperthyroidism in late pregnancy. The plasma insulin:blood glucose concentration ratio in the hyperthyroid group was significantly lower than that of the euthyroid group at $10 \mathrm{~min}$ (euthyroid $66.6 \pm 11.1 \mu \mathrm{U} / \mu \mathrm{mol}$ $[n=6]$; hyperthyroid $22.3 \pm 4.5 \mu \mathrm{U} / \mu \mathrm{mol}[n=8] ; p<0.05)$ and $15 \mathrm{~min}$ (euthyroid $35.2 \pm 7.1 \mu \mathrm{U} / \mu \mathrm{mol}[n=6]$; hyperthyroid $12.3 \pm 2.7 \mu \mathrm{U} / \mu \mathrm{mol}[n=8] ; p<0.05)$ after the i.v. glucose bolus. This response suggested a more rapid return of insulin concentrations to postabsorptive values relative to the decline in glycaemia, introducing the possibility that hyperthyroidism might modify insulin secretion in response to glucose at submaximal concentrations and/or result in more rapid uncoupling of insulin secretion from the glucose stimulus.
Hyperthyroidism during late pregnancy increases the glucose threshold and decreases glucose responsiveness of GSIS with perifused islets We evaluated in detail the impact of hyperthyroidism on the relationship between GSIS and rising or falling extracellular glucose concentra-

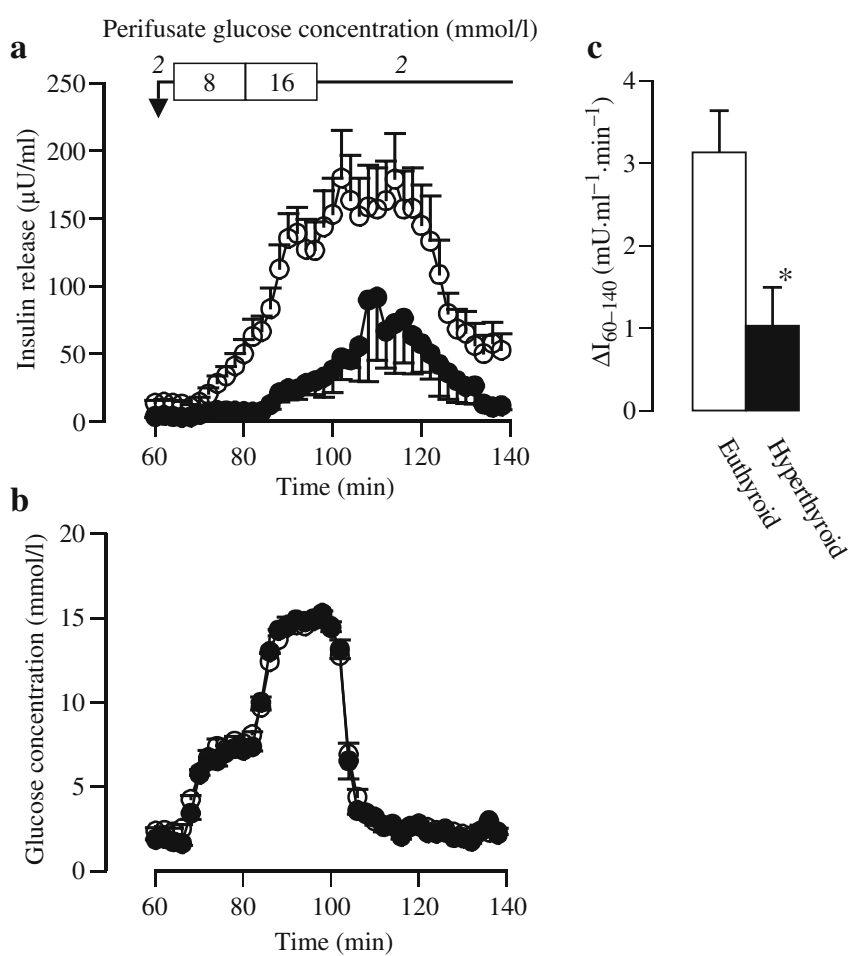

Fig. 2 Hyperthyroidism during late pregnancy suppresses GSIS by isolated perifused islets. Islets isolated from euthyroid (open symbols) or hyperthyroid (closed symbols) 19-day pregnant rats were pre-perifused in medium containing $2 \mathrm{mmol}$ glucose/ 1 for $60 \mathrm{~min}$ at a flow rate of $1 \mathrm{ml} / \mathrm{min}$ at $37^{\circ} \mathrm{C}$. Portions $(2 \mathrm{ml})$ were collected at 2-min intervals and stored at $-20^{\circ} \mathrm{C}$ prior to assays for insulin and glucose. a, b Perifusion profiles for insulin and glucose. Areas under the insulin curves calculated for the period from 60 to $140 \mathrm{~min}\left(\Delta I_{60-140}\right)$ are shown (c) for euthyroid (open bar) or hyperthyroid (closed bar) 19-day pregnant rats. Results are means \pm SEM for nine islet preparations from euthyroid pregnant rats and four islet preparations from hyperthyroid pregnant rats. The significance of differences in response between preparations from hyperthyroid and euthyroid pregnant rats have been omitted for clarity in the perifusion profiles, but are quantified in Table 2. $* p<0.05$ for differences in $\Delta I_{60-140}$ values between islets from hyperthyroid and euthyroid pregnant rats 
Table 3 Steady-state blood glucose and plasma insulin concentrations, and incremental AUC for insulin $\left(\Delta I_{0-60}\right)$ during sustained glucose challenge in vivo in euthyroid or hyperthyroid 19-day pregnant rats

\begin{tabular}{|c|c|c|}
\hline & Euthyroid & Hyperthyroid \\
\hline $\begin{array}{l}\text { Steady-state blood glucose } \\
(\mathrm{mmol} / \mathrm{l})\end{array}$ & $10.1 \pm 0.2(6)$ & $11.4 * * * \pm 0.1$ \\
\hline $\begin{array}{l}\text { Steady-state plasma insulin } \\
(\mu \mathrm{U} / \mathrm{ml})\end{array}$ & $462 \pm 34(6)$ & $553 \pm 50(6)$ \\
\hline $\begin{array}{l}\text { Steady-state plasma insulin : } \\
\text { steady-state blood glucose } \\
\text { concentration ratio }(\mu \mathrm{U} / \mu \mathrm{mol})\end{array}$ & $48.0 \pm 9.3(6)$ & $48.4 \pm 5.6(6)$ \\
\hline$\Delta I_{0-60}\left(\mu \mathrm{U}^{-1} \min ^{-1}\right)$ & $4469 \pm 828(6)$ & $5785 \pm 1334(6)$ \\
\hline
\end{tabular}

Blood glucose and plasma insulin values were measured for seven samples taken between 30 to $60 \mathrm{~min}$ after initiation of glucose infusion for calculation of steady-state concentrations. Insulin responses during the hyperglycaemic clamp were used for calculation of the incremental insulin values integrated over the period of glucose infusion $\left(\Delta I_{0-60}\right)$. Data are means $\pm S E M$, with the numbers of rats in parentheses

$* * * p<0.001$ for difference between euthyroid and hyperthyroid pregnant rats

tions using step-up and step-down islet perifusions generating gradual rises in perifusate glucose concentrations from $2 \mathrm{mmol} / \mathrm{l}$ (basal) to the mid-physiological range $(8 \mathrm{mmol} / \mathrm{l})$, then to the high physiological range $(16 \mathrm{mmol} / \mathrm{l})$, before switching back to $2 \mathrm{mmol}$ glucose/l. To compare insulin secretory responses directly, areas under the insulin curves were calculated for discrete 16-min periods. $\Delta 1$ and $\Delta 2$ (Table 2) refer to periods during which the perifusate glucose concentration was increased from 2 to $8 \mathrm{mmol} / 1$ and from 8 to $16 \mathrm{mmol} / \mathrm{l}$, respectively. Insulin release profiles during islet perifusions and $\Delta I_{60-140}$ values (incremental plasma insulin values integrated over the entire period of islet perifusion) are shown in Fig. 2a, and b, respectively. Raising the perifusate glucose concentration for $16 \mathrm{~min}$ to a mean assayed value of $6.4 \pm 0.2 \mathrm{mmol} / 1$ increased rates of insulin release by islets from euthyroid pregnant rats up to 2.1-fold $(p<0.001)$. Raising perifusate glucose concentration further to a mean assayed value of $13.8 \pm 0.4 \mathrm{mmol} / \mathrm{l}$ led to 8.8 -fold higher rates of insulin release compared with basal rates $(p<0.01)$. Mean peak rates of insulin release were $180 \mu \mathrm{U} / \mathrm{min}$, and $\Delta 2$ was 6.6-fold greater than $\Delta 1 . \mathrm{T}_{3}$ treatment evoked a marked $(71 \%)$ decline in basal rates of insulin release at $2 \mathrm{mmol} / \mathrm{l}$ glucose (euthyroid $14 \pm 2 \mathrm{mU} / \mathrm{min}[n=9]$; hyperthyroid $4 \pm$ $1 \mathrm{mU} / \mathrm{min}[n=4] ; p<0.01)$. This contrasts with the absence of an effect of hyperthyroidism on basal (postabsorptive) insulin levels in vivo, and probably reflects the loss during islet preparation of in vivo factors that elevate basal secretion (e.g. an adaptation to insulin resistance signalled to the islet in vivo). $\Delta 1$ was decreased by $85 \%(p<0.05)$ and $\Delta 2$ was decreased by $81 \%(p<0.001)$ by hyperthyroidism in late pregnancy. Thus, as illustrated in Fig. 2a, hyperthyroidism causes a marked rightward shift in the profile of insulin secretion in response to increasing perifusate glucose concentrations. In addition, hyperthyroidism suppressed mean peak rates of insulin secretion at high glucose concentrations $(37 \% ; p<0.01)$. Overall, the effect of hyperthyroidism during pregnancy on suppression of GSIS in isolated perifused islets is demonstrated by the $67 \%$ decline in $\Delta I_{60-140}$ values (Fig. 2b).

Hyperthyroidism during late pregnancy also suppresses GSIS on removal of the glucose stimulus with perifused islets $\Delta 3$ and $\Delta 4$ (Table 2) refer to periods where the perifusate glucose concentrations were lowered from 16 to $2 \mathrm{mmol} / \mathrm{l}$ and maintained at basal $(2 \mathrm{mmol} / \mathrm{l})$ respectively. Hyperthyroidism in late pregnancy caused 56 and $60 \%$ decreases in $\Delta 3$ and $\Delta 4$ respectively (Table 2). Restoring perifusate glucose concentrations to basal levels resulted in lower insulin secretion rates (steady-state rate of $36 \pm$ $7 \mu \mathrm{U} / \mathrm{min}$ ) in the hyperthyroid pregnant group compared with the euthyroid pregnant group (Fig. 2a). a

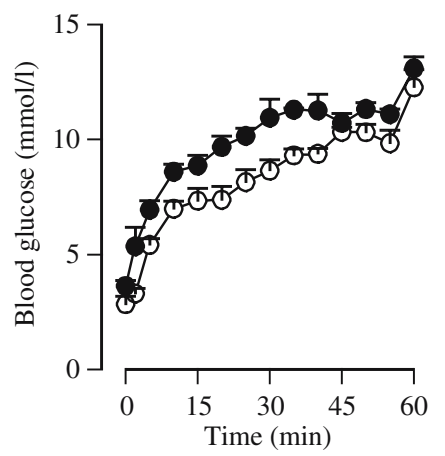

b

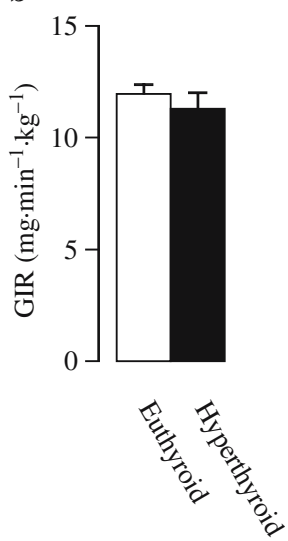

c

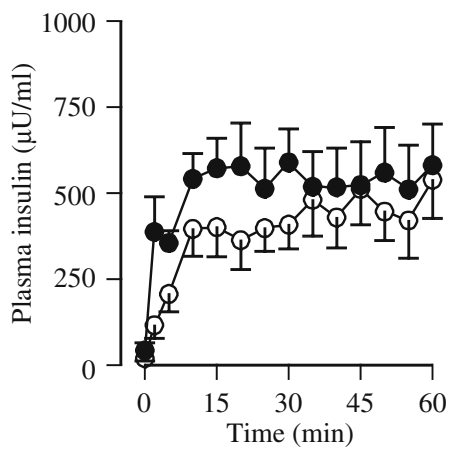

Fig. 3 Effects of hyperthyroidism on insulin secretion during a sustained glucose challenge (hyperglycaemic clamp) in 19-daypregnant rats. Blood samples were drawn from euthyroid (open symbols) or hyperthyroid (closed symbols) 19-day-pregnant rats at intervals during a sustained intravenous glucose challenge. a Blood glucose concentrations. b Steady-state GIR, calculated as mean GIR during the last $30 \mathrm{~min}$ of glucose infusion. c Plasma insulin concentrations. Results are means \pm SEM for six euthyroid pregnant rats and six hyperthyroid pregnant rats 
Hyperthyroidism during late pregnancy does not lower GSIS in response to sustained glucose challenge in vivo We infused glucose at a fixed rate to clamp glucose at a high physiological concentration for a prolonged period (60 $\mathrm{min}$ ) to determine whether GSIS could be sustained in hyperthyroid pregnant rats in vivo. Higher steady-state blood glucose concentrations (Table 3; see also Fig. 3a) were observed in the hyperthyroid than in the euthyroid pregnant group despite a similar GIR (Fig. 3b). Under conditions of sustained hyperglycaemia in vivo, hyperthyroidism in late pregnancy did not lower steady-state insulin levels or suppress $\Delta I_{0-60}$ (Table 3; see also Fig. 3c), contrasting with the results obtained in response to an IVGTT in vivo and during islet perifusions ex vivo involving stepup and step-down changes in perifusate glucose concentrations. The steady-state plasma insulin concentration: steady-state blood glucose concentration ratio during the hyperglycaemic clamp was unaffected by hyperthyroidism during late pregnancy (Table 3 ).

Liporegulation by insulin is impaired in the hyperthyroid pregnancy NEFA profiles were obtained before and during the sustained hyperglycaemic clamps. Hyperthyroidism did not affect postabsorptive (basal) plasma NEFA concentrations in pregnant rats (Fig. 4a). In euthyroid pregnant rats, plasma NEFA fell rapidly after initiating glucose infusion, with maximal suppression within $20 \mathrm{~min}$. Steady state was reached after 30-60 min, at which time plasma NEFA concentrations had been suppressed to $27 \%$ of basal values (Fig. 4a). Glucose infusion also suppressed plasma NEFA concentrations in hyperthyroid pregnant rats, but steady-state (30-60 min) plasma NEFA levels during hyperinsulinaemia in hyperthyroid pregnant rats remained at $51 \%$ of corresponding basal values, significantly higher than steady-state plasma NEFA levels in euthyroid pregnant rats (by 2-fold, $p<0.001$ ) (Fig. 4a). Hence, insulin
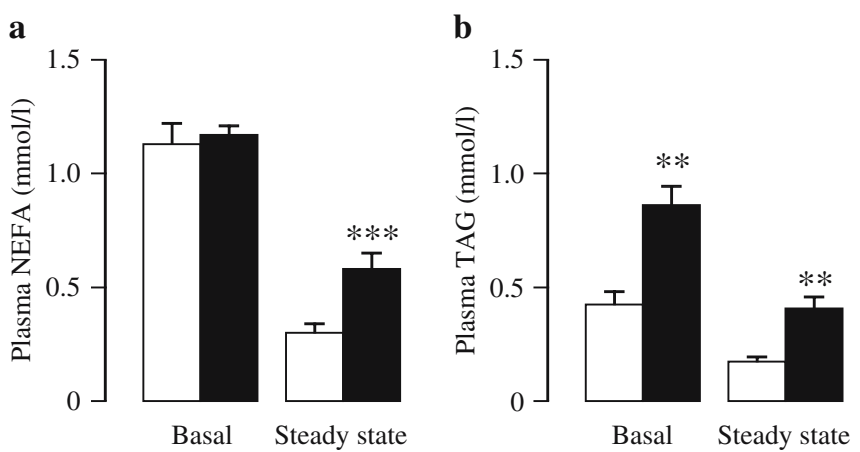

Fig. 4 Influence of hyperthyroidism on plasma NEFA and TAG concentrations before and at steady state during a sustained glucose challenge (hyperglycaemic clamp) in 19-day-pregnant rats. Blood samples were drawn from euthyroid (open bars) or hyperthyroid (closed bars) 19-day-pregnant rats at intervals after a sustained intravenous glucose challenge for measurement of plasma NEFA (a) and TAG (b) concentrations. Steady-state concentrations of plasma NEFA and TAG were calculated as means of values for seven samples taken from 30 to 60 min after initiation of glucose infusion. Results are means \pm SEM for six euthyroid pregnant rats and six hyperthyroid pregnant rats. ${ }^{*} p<0.01$ and $* * * \mathrm{p}<0.001$ for differences between euthyroid and hyperthyroid pregnant rats hypersecretion in the hyperthyroid pregnant state only partially compensates for maternal insulin resistance with respect to suppression of circulating NEFA concentrations.

NEFA are the major precursors for hepatic VLDLTAG secretion. Plasma TAG values before and during the hyperglycaemic clamps are shown in Fig. 4a. Postabsorptive plasma TAG concentrations were increased two-fold $(p<0.01)$ by hyperthyroidism in late pregnancy. In both euthyroid and hyperthyroid pregnant rats, plasma TAG concentrations declined after initiating glucose infusion. Steady-state (30-60 min) TAG concentrations during hyperinsulinaemia remained significantly higher (2.4-fold; $p<0.01)$ in hyperthyroid than in euthyroid pregnant rats.

\section{Discussion}

Physiological insulin resistance occurs during late pregnancy [35]. This is normally accompanied by a lowered glucose threshold for insulin secretion and increased insulin secretion at high glucose concentration [5, 36, 37], which compensates for the development of insulin resistance so that glucose tolerance is maintained. We found that hyperthyroidism during late gestation targeted both of these stable pancreatic beta cell adaptations to pregnancy. Our perifused islet studies revealed a marked rightward shift in insulin secretion in response to increasing glucose concentration, as demonstrated by a significant reduction in the value for $\Delta 1$, indicating an increased glucose threshold for insulin secretion in response to the induction of hyperthyroidism during pregnancy. In addition, hyperthyroidism blunted GSIS after an acute glucose challenge in vivo and at both mid and high glucose concentrations with perifused islets in vitro. Finally, hyperthyroidism in late pregnancy led to more rapid suppression of insulin secretion following removal of the glucose stimulus to secretion after bolus glucose administration in the intact animal.

To test whether more rapidly curtailed insulin secretion in hyperthyroid pregnant rats after acute glucose challenge in vivo reflected depletion of islet insulin stores, we examined the response of GSIS in vivo to a sustained glucose challenge. In marked contrast to data obtained after transient increases in extracellular glucose, no impairment of GSIS was evident under conditions of sustained glucose delivery (hyperglycaemic clamp); hyperthyroidism in late pregnancy did not lower steady-state insulin levels or suppress $\Delta I_{0-60}$ during sustained glucose infusion in vivo. Although abnormal glucose tolerance is observed in hyperthyroidism in the non-pregnant state [38] and postabsorptive glycaemia and steady-state glucose levels during glucose infusion were higher in hyperthyroid compared with euthyroid pregnant rats, the steady-state plasma insulin concentrations:steady-state blood glucose concentrations ratio during sustained glucose infusion was unaffected by hyperthyroidism (Table 3). This indicates that insulin secretion in hyperthyroid pregnant rats is appropriate for the level of glycaemia when glucose concentrations are maintained at relatively high levels. The lowered $k$ values seen after acute glucose challenge in the hyperthyroid pregnant 
group therefore reflect the suppression by hyperthyroidism of insulin secretion in vivo as glucose concentrations decline to the low physiological range. Steady-state NEFA levels during hyperinsulinaemia remained higher in the hyperthyroid pregnant group and plasma TAG levels both in the basal state and during steady-state hyperinsulinaemia were also elevated in hyperthyroid compared with euthyroid pregnant rats.

Our in vivo data thus show that high rates of GSIS, albeit inadequate to normalise plasma lipids, can be maintained at sustained high glucose levels in the hyperthyroid pregnant state, but insulin secretion is impaired and curtailed during transient hyperglycaemia in vivo. Thus, in vivo factors specific to sustained (but not transient) hyperglycaemia are able to 'rescue' the impairment of GSIS induced by hyperthyroidism in late pregnancy.

Islet lipid deprivation abolishes GSIS and impaired GSIS after fasting can be reversed by exogenous lipid [3941]. Artificial lowering of malonyl-CoA levels enhances mitochondrial fatty acid oxidation at high glucose concentrations, reduces partitioning of fatty acid into lipid esterification products and suppresses GSIS in clonal beta cells [42]. Suppression of GSIS has been attributed to curtailment of lipid signalling to GSIS [42]. As hyperthyroidism increases fatty acid oxidation [43-45], we propose that the inability to initiate or sustain GSIS during transition periods of increasing or declining glycaemia in vivo in the hyperthyroid pregnancy reflects the accelerated removal of a lipid esterification product that functions as a 'coupling factor' for GSIS. Thus, the inability of hyperinsulinaemia to suppress plasma lipid levels under conditions of the hyperglycaemic clamp in the hyperthyroid state allows sustained delivery of lipid in addition to glucose to the islet, preserving GSIS, because these conditions allow regeneration of lipid esterification products within the islet.

In the present study, hyperthyroidism during late gestation was associated with an increase in fetal weight. The inability to sustain insulin secretion during transient glucose challenge in vivo and/or impaired maternal liporegulation will increase the supply of glucose to the fetus. Fetal macrosomia in response to prolonged hyperglycaemia is also observed during gestational diabetes. It is therefore proposed that the elevated basal glycaemia, together with glucose intolerance due to the blunting and/or curtailing effect of hyperthyroidism on insulin secretion in response to acute hyperglycaemia in vivo in late pregnancy, may underlie the observed increase in fetal weight in hyperthyroid pregnancy.

In summary, we show that insulin secretion during sustained hyperglycaemia in vivo is not impaired by hyperthyroidism during pregnancy, but the insulin secretory response to glucose is blunted at low and high glucose concentrations during islet perifusions ex vivo and more rapidly curtailed after acute glucose challenge in vivo. Since hyperthyroidism in pregnancy also impairs the ability of insulin to suppress systemic lipid levels, we suggest that higher circulating lipids can preserve GSIS in the hyperthyroid pregnancy, provided glucose delivery remains at high levels to suppress islet lipid oxidation and/or allow the formation of lipid esterification products that optimise GSIS.

Acknowledgements This study was supported in part by a project grant from the Wellcome Trust (060965). G. K. Greenwood is a recipient of a Diabetes UK studentship. We thank Loranne Agius for helpful discussion.

\section{References}

1. Bergman RN, Phillips LS, Cobelli C (1981) Physiologic evaluation of factors controlling glucose tolerance in man: measurement of insulin sensitivity and beta-cell glucose sensitivity from the response to intravenous glucose. J Clin Invest 68:1456-1467

2. Kahn SE, Prigeon RL, McCulloch DK et al (1993) Quantification of the relationship between insulin sensitivity and beta-cell function in human subjects. Evidence for a hyperbolic function. Diabetes 42:1663-1672

3. Bergman RN, Finegood DT, Kahn SE (2002) The evolution of beta-cell dysfunction and insulin resistance in type 2 diabetes. Eur J Clin Invest 32(Suppl 3):35-45

4. Leturque A, Ferre P, Burnol AF, Kande J, Maulard P, Girard J (1986) Glucose utilization rates and insulin sensitivity in vivo in tissues of virgin and pregnant rats. Diabetes 35:172-177

5. Sugden MC, Greenwood GK, Smith ND, Holness MJ (2003) Peroxisome proliferator-activated receptor-alpha activation during pregnancy attenuates glucose-stimulated insulin hypersecretion in vivo by increasing insulin sensitivity, without impairing pregnancy-induced increases in beta-cell glucose sensing and responsiveness. Endocrinology 144:146-153

6. Holness MJ, Sugden MC (1997) Glucoregulation during progressive starvation in late pregnancy in the rat. Am J Physiol 272:E556-E561

7. Sugden MC, Holness MJ (1998) Fuel selection: the maternal adaptation to fetal nutrient demand. Biochem Soc Trans 26:7986

8. Buchanan TA, Metzger BE, Freinkel N, Bergman RN (1990) Insulin sensitivity and B-cell responsiveness to glucose during late pregnancy in lean and moderately obese women with normal glucose tolerance or mild gestational diabetes. Am J Obstet Gynecol 162:1008-1014

9. Metzger BE, Bybee DE, Freinkel N, Phelps RL, Radvany RM, Vaisrub N (1985) Gestational diabetes mellitus. Correlations between the phenotypic and genotypic characteristics of the mother and abnormal glucose tolerance during the first year postpartum. Diabetes 34(Suppl 2):111-115

10. Holness MJ, Sugden MC (1999) Antecedent protein restriction exacerbates development of impaired insulin action after highfat feeding. Am J Physiol 276:E85-E93

11. Zammit VA, Waterman IJ, Topping D, McKay G (2001) Insulin stimulation of hepatic triacylglycerol secretion and the etiology of insulin resistance. J Nutr 131:2074-2077

12. Boden G (1997) Role of fatty acids in the pathogenesis of insulin resistance and NIDDM. Diabetes 46:3-10

13. Shulman GI (2000) Cellular mechanisms of insulin resistance. $\mathrm{J}$ Clin Invest 106:171-176

14. Paolisso G, Tataranni PA, Foley JE, Bogardus C, Howard BV, Ravussin E (1995) A high concentration of fasting plasma nonesterified fatty acids is a risk factor for the development of NIDDM. Diabetologia 38:1213-1217

15. Charles MA, Eschwege E, Thibult N et al (1997) The role of non-esterified fatty acids in the deterioration of glucose tolerance in Caucasian subjects: results of the Paris Prospective Study. Diabetologia 40:1101-1106

16. Chaves JM, Herrera E (1978) In vitro glycerol metabolism in adipose tissue from fasted pregnant rats. Biochem Biophys Res Commun 85:1299-1306 
17. Knopp RH, Herrera E, Freinkel N (1970) Carbohydrate metabolism in pregnancy: 8. Metabolism of adipose tissue isolated from fed and fasted pregnant rats during late gestation. J Clin Invest 49:1438-1446

18. Skryten A, Johnson P, Samsioe G, Gustafson A (1976) Studies in diabetic pregnancy: I. Serum lipids. Acta Obstet Gynecol Scand 55:211-215

19. Martin-Hidalgo A, Holm C, Belfrage P, Schotz MC, Herrera E (1994) Lipoprotein lipase and hormone-sensitive lipase activity and mRNA in rat adipose tissue during pregnancy. Am J Physiol 266:E930-E935

20. Fryer LG, Holness MJ, Sugden MC (1997) Selective modification of insulin action in adipose tissue by hyperthyroidism. J Endocrinol 154:513-522

21. Lenzen S, Bailey CJ (1984) Thyroid hormones, gonadal and adrenocortical steroids and the function of the islets of Langerhans. Endocr Rev 5:411-434

22. Becks GP, Burrow GN (1991) Thyroid disease and pregnancy. Med Clin North Am 75:121-150

23. Riis AL, Gravholt CH, Djurhuus CB et al (2002) Elevated regional lipolysis in hyperthyroidism. J Clin Endocrinol Metab $87: 4747-4753$

24. Silvestri E, Moreno M, Lombardi A et al (2005) Thyroidhormone effects on putative biochemical pathways involved in UCP3 activation in rat skeletal muscle mitochondria. FEBS Lett 579:1639-1645

25. Moller N, Nielsen S, Nyholm B, Porksen N, Alberti KG, Weeke J (1996) Glucose turnover, fuel oxidation and forearm substrate exchange in patients with thyrotoxicosis before and after medical treatment. Clin Endocrinol (Oxf) 44:453-459

26. Tene C, Zarate A, Basurto L et al (2001) Correction of insulin resistance in methimazole-treated patients with Graves disease. Rev Invest Clin 53:531-535

27. Fukuchi M, Shimabukuro M, Shimajiri Y et al (2002) Evidence for a deficient pancreatic beta-cell response in a rat model of hyperthyroidism. Life Sci 71:1059-1070

28. Jorns A, Tiedge M, Lenzen S (2002) Thyroxine induces pancreatic beta cell apoptosis in rats. Diabetologia 45:851-855

29. Sugden MC, Liu YL, Holness MJ (1990) Glucose utilization by skeletal muscles in vivo in experimental hyperthyroidism in the rat. Biochem J 271:421-425

30. Thibodeaux JR, Hanson RG, Rogers JM et al (2003) Exposure to perfluorooctane sulfonate during pregnancy in rat and mouse: I. Maternal and prenatal evaluations. Toxicol Sci 74: 369-381

31. Sugden MC, Langdown ML, Harris RA, Holness MJ (2000) Expression and regulation of pyruvate dehydrogenase kinase isoforms in the developing rat heart and in adulthood: role of thyroid hormone status and lipid supply. Biochem J 352:731738
32. Holness MJ (1996) Impact of early growth retardation on glucoregulatory control and insulin action in mature rats. Am J Physiol 270:E946-E954

33. Hughes SJ, Carpinelli A, Niki I, Nicks JL, Ashcroft SJ (1992) Stimulation of insulin release by vasopressin in the clonal beta-cell line, HIT-T15: the role of protein kinase C. J Mol Endocrinol 8:145-153

34. Holness MJ, Sugden MC (2001) Dexamethasone during late gestation exacerbates peripheral insulin resistance and selectively targets glucose-sensitive functions in beta cell and liver. Endocrinology 142:3742-3748

35. Bliss CR, Wiedenkeller DE, Sharp GW (1990) Maternal diet and insulin secretion in islets of lactating, nonlactating, and young rats. Am J Physiol 259:E568-E575

36. Green IC, Taylor KW (1972) Effects of pregnancy in the rat on the size and insulin secretory response of the islets of Langerhans. J Endocrinol 54:317-325

37. Sorenson RL, Brelje TC (1997) Adaptation of islets of Langerhans to pregnancy: beta-cell growth, enhanced insulin secretion and the role of lactogenic hormones. Horm Metab Res 29:301-307

38. Wajchenberg BL, Cesar FP, Leme CE, Souza IT, Pieroni RR, Mattar E (1978) Carbohydrate metabolism in thyrotoxicosis: studies on insulin secretion before and after remission from the hyperthyroid state. Horm Metab Res 10:294-299

39. Dobbins RL, Chester MW, Daniels MB, McGarry JD, Stein DT (1998) Circulating fatty acids are essential for efficient glucosestimulated insulin secretion after prolonged fasting in humans. Diabetes 47:1613-1618

40. Stein DT, Esser V, Stevenson BE et al (1996) Essentiality of circulating fatty acids for glucose-stimulated insulin secretion in the fasted rat. J Clin Invest 97:2728-2735

41. McGarry JD, Dobbins RL (1999) Fatty acids, lipotoxicity and insulin secretion. Diabetologia 42:128-138

42. Roduit R, Nolan C, Alarcon C et al (2004) A role for the malonyl-CoA/long-chain acyl-CoA pathway of lipid signaling in the regulation of insulin secretion in response to both fuel and nonfuel stimuli. Diabetes 53:1007-1019

43. Paradies G, Ruggiero FM, Petrosillo G, Quagliariello E (1996) Stimulation of carnitine acylcarnitine translocase activity in heart mitochondria from hyperthyroid rats. FEBS Lett 397: 260-262

44. Mynatt RL, Park EA, Thorngate FE, Das HK, Cook GA (1994) Changes in carnitine palmitoyltransferase-I mRNA abundance produced by hyperthyroidism and hypothyroidism parallel changes in activity. Biochem Biophys Res Commun 201:932-937

45. Bech K, Damsbo P, Eldrup E et al (1996) Beta-cell function and glucose and lipid oxidation in Graves' disease. Clin Endocrinol (Oxf) 44:59-66 